\title{
Pengembangan Sistem Basis Data dalam Pembuatan Aplikasi Monitoring Call Center
}

\author{
Nunu Kustian, Aan Risdiana, Dudi Parulian \\ Universitas Indraprasta PGRI \\ Jl. Raya Tengah Kel. Gedong, Pasar Rebo - Jakarta Timur \\ E-mail : kustiannunu@gmail.com; Risdi_Ann@live.com ; dudiparulian@gmail.com
}

\begin{abstract}
Abstrak - Tujuan penelitian ini adalah untuk membuat aplikasi monitoring call center dalam mencegah terjadinya tindakan diskriminatif, memudahkan laporan kepada atasan, dan memonitoring konsistensi terhadap customer service dengan dengan menganalisis dan merancang sistem basis data didalam aplikasi tersebut. Masalah yang dihadapi oleh Badan Penanggulangan Bencana Daerah Provinsi DKI Jakarta adanya kesulitan dalam memantau efisiensi agen call center, memantau keterlibatan agen customer service dalam melayani panggilan pekerjaan, dan pemeriksaan cepat secara real time. Metode yang digunakan dalam penelitian ini menggunakan Fact Finding yang dilakukan dengan studi langsung ke lapangan pihak terkait, wawancara, dan mempelajari dokumentasi perusahaan yang ditindaklanjuti dengan studi kepustakaan.. Hasil dari pembuatan aplikasi monitoring call center ini memudahkan pengawas dalam memonitoring setiap agen call center tanpa mengganggu percakapan dengan pelanggan dan meningkatkan produktivitas pada tingkat yang lebih tinggi dan setiap agen call center dapat menjaga hubungan dengan pelanggan dengan tujuan kualitas pelayanan terhadap pelanggan dengan pihak terkait.
\end{abstract}

Kata kunci: Call Center, Customer Service, Monitoring, Penilaian

\section{PENDAHULUAN}

112 Jakarta Siaga adalah layanan call center untuk masyarakat yang didirikan oleh Koordinasi Badan Penanggulangan Bencana Daerah dimana datanya diintegrasi langsung dari Dinas Kominfomas Provinsi DKI Jakarta yang berupa Smart City saat mengatasi keluhan masyarakat dimana masyarakat sebagai customer akan dipandu lalu diberikan saran dalam melakukan tindakantindakan yang sesuai dengan masalahnya oleh petugas call center.

Pelayanan 112 Jakarta Siaga dalam pelayanannya dijadikan solusi yang sangat tepat dan efektif dalam meningkatkan kebutuhan customer dalam hal ini adalah masyarakat.. Pada umumnya masyarakat sangat membutuhkan informasi secara cepat. Tentu saja masyarakat yang menjadi customer ingin tahu tentang suatu keadaan, pengaduan, ataupun menanyakan informasi yang dibutuhkan. Informasi menjadi salah satu hal yang penting dalam proses pengambilan keputusan bukan hanya harus cepat, kredibel dan berkualitas, tetapi juga harus memberikan gambaran yang utuh.

Tugas pengembangan call center dalam melayani customer bukan hal mudah yang beroperasi sepanjang malam dan tentu saja secara langsung harus memiliki petugas layanan yang berkompeten dan kegiatan call center memerlukan kinerja yang sesuai dijalurnya. Dalam penilaian call center, sangat diperlukannya indikator- indikator yang berkaitan dengan tugasnya sebagai call center khususnya di Badan Penanggulan Bencana Daerah (BPBD) Provinsi DKI Jakarta yang selalu berkomitmen untuk memberikan pelayanan terbaik kepada masyarakatnya. Salah satunya lewat layanan nomor tunggal darurat Jakarta Siaga 112. Tantangan bagi para agen adalah terbatasnya jumlah agen call center yang berkualitas dan terlatih untuk menanggapi pelanggan.

Dengan adanya dukungan Global Positioning System (GPS) yang sudah tersedia diperangkat petugas lapangan dimanfaatkan agar petugas lapangan diarahkan langsung datang cepat ke lokasi kejadian yang telah dihubungi oleh agen call center. Untuk itu, setiap agen call center harus benar-benar dilihat keterampilannya dalam menanggapi semua keluhan, dan siap siaga dalam mengatasi telepon dari pelanggan. Tujuan dari penelitian ini fokus terhadap pengembangan sistem data dalam pembuatan aplikasi monitoring call center yang mampu memberikan keputusan dalam memilih agen call center terbaik dari segi pelayanan, tanggapan, dan penyelesaian masalah yang dimonitoring secara langsung oleh pengawas call center BPBD DKI Jakarta.

\section{LANDASAN TEORI}

Penulis mengambil beberapa referensi penelitian yang berkaitan dengan penelitian yang dilakukan. Berikut referensi penelitian: 
Penelitian yang dilakukan [1] menunjukkan bahwa sistem yang basis data yang dikembangkan dari sistem yang sudah ada yaitu sistem informasi manajemen Sumber Daya Manusia (SDM) sesuai dengan kebutuhan manajemen SDM yang diperlukan dengan dilibatkannya berbagai pihak dalam organisasi sehingga mulai dari desain sampai pelaporan serta codingan dalam program yang dibuat sesuai dengan aplikasi yang diharapkan dengan metodologi penelitiannya digambarkan melalui tahapan setiap proses yang dibutuhkan, dan alat bantu dalam hal ini menggunakan perancangan skema konseptual database, transaksi, dan pengimplementasiannya.

Begitu juga dengan penelitian yang dilakukan [2] bahwa hasil penelitian tersebut melalukan kajian pengembangan yang dilakukan terhadap pelayanan akademik khususnya dalam data warehouse call center pada Divisi Informasi Publik Sarana Informatika yang sangat berguna bagi operasional dan pelayanan kualitas akademik. Penelitian tersebut menggunakan metode kimball nine-step, data warehouse call center pada aplikasi tersebut menjadi aplikasi presentasi berbasis web yang dapat diakses kapan saja dan dimana saja dengan mudah sebingga tujuannya dalam meningkatkan pelayanan akademik sangat berguna dalam memenuhi kebutuhan perencanaan, pengevaluasian sampai pengambilan keputusan.

Berdasarkan hasil penelitian yang dilakukan [3] dengan menggunakan metode action research yang dimana penelitiannya berfokus kepada tindakan sosial dengan metode pengembangan basis data life cycle. Dengan tujuannya adalah untuk melakukan rancangan active database sistem terhadap pelayanan harga pasar untuk menghasilkan aplikasi yang dapat bekerjasama sehingga sangat responsif terhadap sistem kembali pada modem yang diterapkan ke dalam masyarakat, namun sistem yang dibangun masih dalam proses desain perancangan database sehingga membutuhkan penelitian lebih lanjut.

\section{METODOLOGI PENELITIAN}

Penulis menggunakan Metode Fact Finding yang digunakan pada waktu awal, maupun saat-saat penting dari sebuah life cycle. Metode ini digunakan untuk menemukan fakta-fakta yang terjadi baik dilapangan saat agen call center memberikan pelayanan maupun saat pengumpulan data. Langkah-langkahnya adalah:

\section{a. Examining Documentation}

Bertujuan untuk melakukan pemeriksaan dokumen yang telah ada, formulir, laporan, dan data-data yang berhubungan dengan sistem.

b. Interviewing

Mewawancarai pertanyaan yang spesifik untuk diajukan sebagai narasumber. Biasanya dilakukan secara face to face.

c. Observasing the Enterprise in Operation

Dengan teknik ini, penulis mengobservasi pelaksanaan dan tidak menutup kemungkinan agen call center dipantau saat tugasnya berlangsung.

\section{d. Research}

Penelitian dilakukan oleh penulis untuk melihat apakah ada masalah atau kendala terhadap aplikasi dan dicari informasi apa saja yang dapat mendukung pengembangan sistem dalam mengambil sebuah keputusan.

\section{e. Questionaires}

Peneliti melakukan beberapa pertanyaan dengan teknik mengedepankan kebebasan responden dalam menjawab pertanyaan.

Sistem keputusan yang dibuat berdasarkan penilaian skala likert. Penulis menggunakan skala likert untuk mengukur setiap score yang diberikan dan bobot setiap scorenya. Skala 1= Kurang, Skala 2= Cukup, Skala 3= Baik, Skala 4= Sangat Baik.

Berikut salah satu contoh kriteria pertanyaan dari setiap score yang diberikan :

Tabel 1 Contoh Perhitungan Skala dan Bobot Berdasarkan Setiap Kriteria

\begin{tabular}{|l|l|l|}
\hline Kriteria & Skala & Bobot (\%) \\
\hline \multirow{3}{*}{ Salam Pembuka } & 1 & 0,25 \\
\cline { 2 - 3 } & 2 & 0,5 \\
\cline { 2 - 3 } & 3 & 0,75 \\
\cline { 2 - 3 } & 4 & 1 \\
\hline
\end{tabular}

Berdasarkan tabel tersebut, bahwa kriteria pertanyaan memiliki kontribusi sebesar $2 \%$ dari score yang dipilih.

\section{HASIL DAN PEMBAHASAN}

Untuk rancangan pengembangan sistem basis data yang dibuat dengan bahasa pemrograman dengan menggunakan alat bantu yang digunakan untuk menerangkan logika program yang dibuat adalah flowchart. Berikut flowchart rancangan aplikasi yang dibuat:

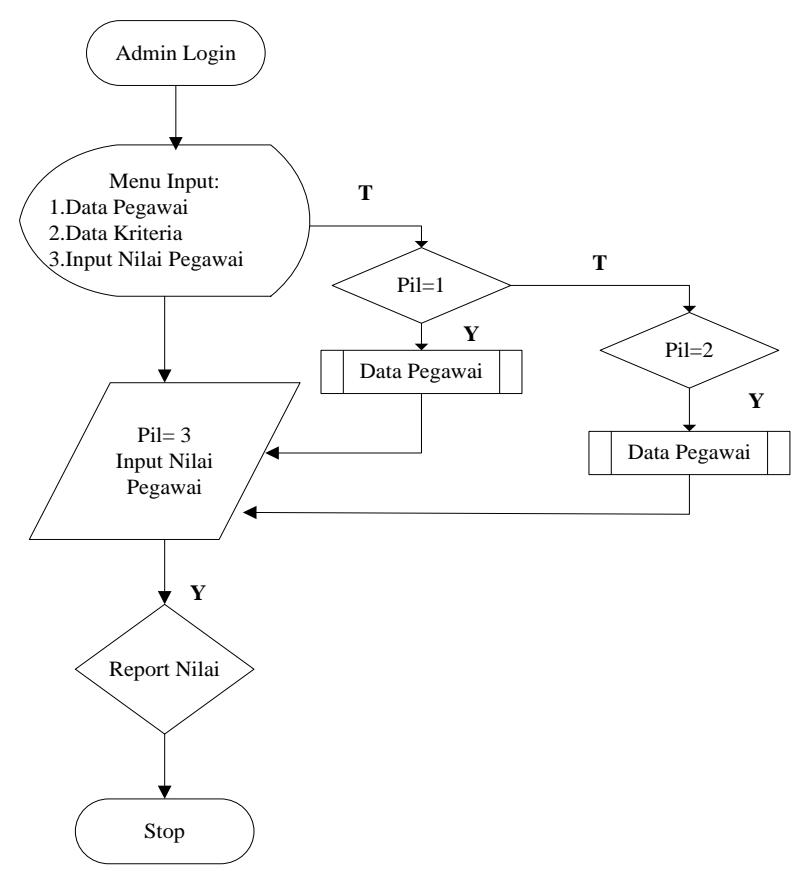

Gambar 1. Flowchart Aplikasi Monitoring Call Center 


\section{Use Case Diagram}

Berfungsi untuk menjelaskan interaksi atau hubungan aktor di dalam sistem monitoring call center:

Tabel 1. Identifikasi Aktor dan Use Case

\begin{tabular}{|l|c|l|}
\hline No. & Aktor & \multicolumn{1}{c|}{ Deskripsi } \\
\hline 1 & Admin & $\begin{array}{l}\text { Orang yang meng-input data agen call } \\
\text { center, nilai agen call center, skala, dan } \\
\text { kriteria agen call center dan membuat } \\
\text { print out hasil penilaian }\end{array}$ \\
\hline 2 & Manager & $\begin{array}{l}\text { Orang yang menerima laporan penilaian } \\
\text { yang di input oleh Admin dan bisa juga } \\
\text { bertindak sebagai Admin. }\end{array}$ \\
\hline
\end{tabular}

Berikut menjelaskan interaksi aktor dengan sistem yang menjadi sebuah use case.

Tabel 2. Daftar Diagram Use Case Proses Penilaian Agen Call Center

\begin{tabular}{|c|c|c|c|}
\hline $\begin{array}{l}\mathbf{N} \\
\mathbf{0 .}\end{array}$ & $\begin{array}{c}\text { Use Case } \\
\text { Name }\end{array}$ & Deskripsi & Aktor \\
\hline 1. & Login & $\begin{array}{l}\text { Use Case menggambarkan } \\
\text { kegiatan mengisi username } \\
\text { dan password untuk masuk } \\
\text { ke dalam sistem. }\end{array}$ & Admin \\
\hline 2. & $\begin{array}{l}\text { Input Data } \\
\text { Pegawai }\end{array}$ & $\begin{array}{lr}\text { Use case menggambarkan } \\
\text { kegiatan } & \text { menginput } \\
\text { informasi data pegawai }\end{array}$ & Admin \\
\hline 3. & $\begin{array}{l}\text { Input Data } \\
\text { Kriteria }\end{array}$ & $\begin{array}{l}\text { Use case menggambarkan } \\
\text { kegiatan menginput data } \\
\text { kriteria dan bobot kriteria } \\
\text { untuk setiap masing-masing } \\
\text { agen call center. }\end{array}$ & Admin \\
\hline 4. & $\begin{array}{l}\text { Input Nilai } \\
\text { Pegawai }\end{array}$ & $\begin{array}{l}\text { Use case menggambarkan } \\
\text { kegiatan menginput data } \\
\text { kriteria dan nilai per kriteria } \\
\text { beserta periode untuk setiap } \\
\text { masing-masing agen call } \\
\text { center. }\end{array}$ & Admin \\
\hline 5. & Report Nilai & $\begin{array}{l}\text { Use case menggambarkan } \\
\text { kegiatan laporan/report nilai } \\
\text { yang didapat setelah peng } \\
\text { inputan nilai pegawai/agen } \\
\text { call center untuk setiap } \\
\text { masing-masing agen call } \\
\text { center. }\end{array}$ & Admin \\
\hline 6. & $\begin{array}{l}\text { Manajemen } \\
\text { User }\end{array}$ & $\begin{array}{l}\text { Use case menggambarkan } \\
\text { kegiatan manajemen user } \\
\text { yang bisa di update dan di } \\
\text { delete sebagai admin. }\end{array}$ & Admin \\
\hline 7. & Setting Skala & $\begin{array}{l}\text { Use case menggambarkan } \\
\text { kegiatan setting skala likert } \\
\text { dari } 1-4 \text {, persentase skala, } \\
\text { dan inisial dari skalanya. }\end{array}$ & Admin \\
\hline
\end{tabular}

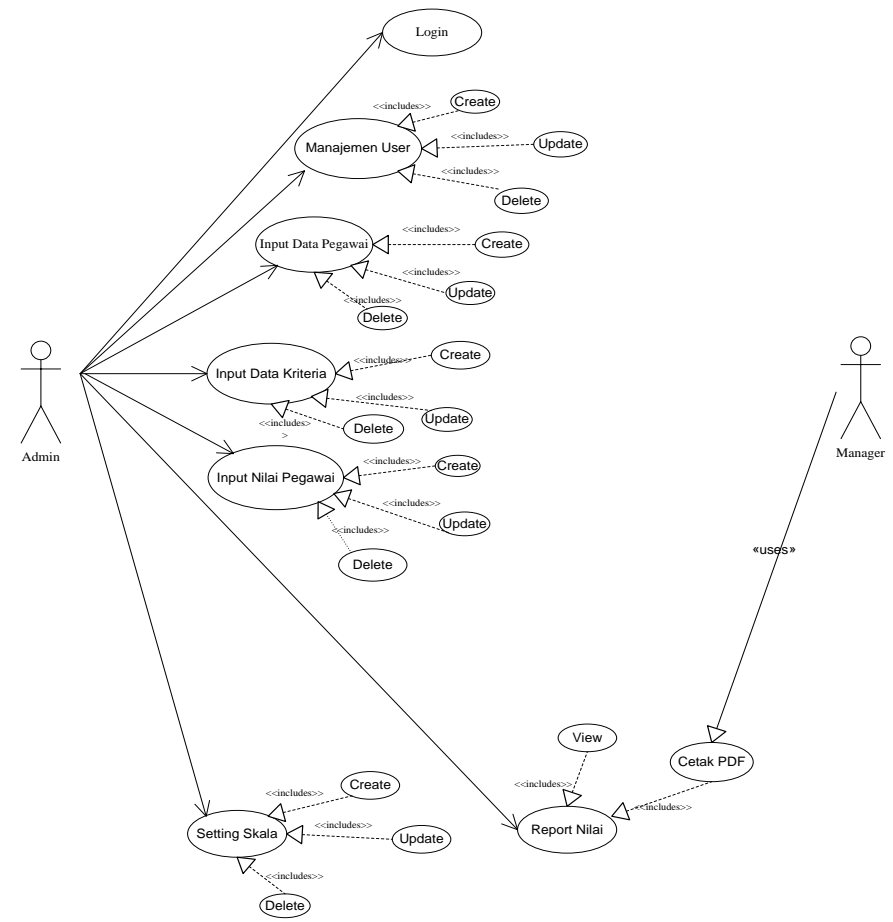

Gambar 2. UML Monitoring Call Center

Pada gambar 2, menunjukkan bahwa admin memegang kendali penuh terhadap aplikasi monitoring call center untuk melakukan penilaian terhadap kinerja call center, mulai dari penginputan data pegawai/agen call center, input kriteria yang dimiliki setiap pegawai/agen call center, lalu berdasarkan kriteria yang dimiliki, admin melakukan input nilai pegawai/agen call center dan akan dijadikan laporan yang akan disiapkan untuk manager.

\section{Analisa Proses}

Tujuan analisa proses ini adalah untuk mengetahui proses yang sedang berjalan atau terjadi dimana proses ini terlihat pada activity diagram berikut ini:

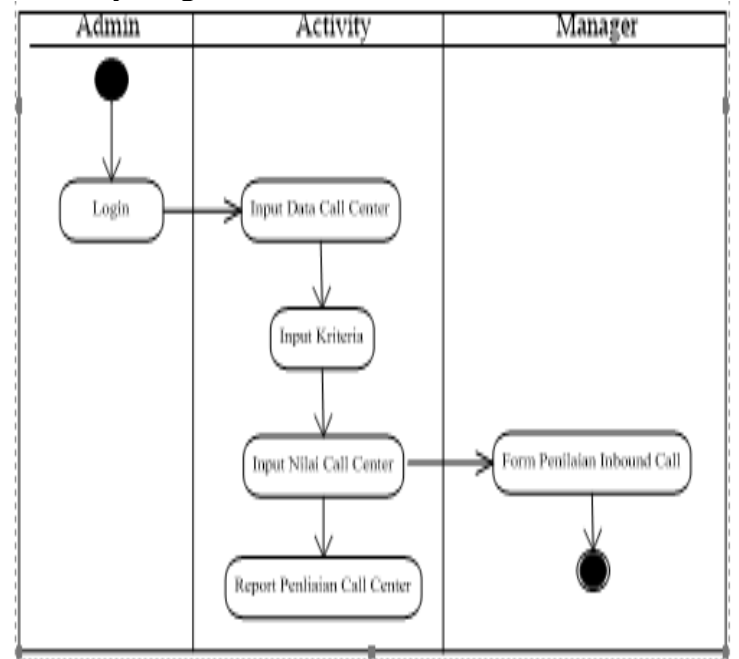

Gambar 3. Activity Diagram Sistem Monitoring Call Center 
Implementasi Sistem Basis Data

Berikut pengembangan sistem database setiap menu yang diperlukan pada aplikasi monitoring call center:

Tabel 3. Tabel Analisa

\begin{tabular}{|l|l|l|}
\hline \multicolumn{1}{|c|}{ Name } & \multicolumn{1}{|c|}{ Null } & \multicolumn{1}{c|}{ Type } \\
\hline Id_analisa & No & Int (11) \\
\hline Id_pegawai & Yes & Int (11) \\
\hline Id_kriteria & Yes & Int (11) \\
\hline nilai & Yes & Varchar (8) \\
\hline \multicolumn{1}{|c|}{ Tabel analisa }
\end{tabular}

berhubungan dengan kriteria masing-masing agen call center yang akan dinilai yang kemudian akan dianalisa apakah memenuhi standar penilaian dalam kegiatan call center.

Tabel 4. Tabel Kriteria

\begin{tabular}{|l|l|l|}
\hline \multicolumn{1}{|c|}{ Name } & \multicolumn{1}{|c|}{ Null } & \multicolumn{1}{c|}{ Type } \\
\hline Id_kriteria & No & Int (11) \\
\hline Kriteria & Yes & Text \\
\hline Bobot & Yes & Varchar (5) \\
\hline
\end{tabular}

Tabel kriteria digunakan untuk mengelola penilaian melalui tahap-tahap kriteria yang sudah ditentukan dan akan diberikan bobot dari masing-masing kriteria yang diberikan.

Tabel 5. Tabel Pegawai

\begin{tabular}{|l|l|l|}
\hline \multicolumn{1}{|c|}{ Name } & \multicolumn{1}{c|}{ Null } & Type \\
\hline Id_pegawai & No & Varchar (10) \\
\hline Nama_lengkap & No & Varchar (50) \\
\hline Tempat_lahir & No & Varchar (30) \\
\hline Tanggal_lahir & No & Varchar (30) \\
\hline Alamat & No & Varchar (50) \\
\hline No_hp & No & Varchar (10) \\
\hline Jabatan & No & Varchar (15) \\
\hline Status & No & Varchar (10) \\
\hline
\end{tabular}

Tabel pegawai menyimpan informasi tentang data diri pegawai yang akan menilai setiap agen call center baik manager maupun staff yang diberikan surat tugas untuk memonitoring kegiatan call center.

Tabel 6. Tabel Nilai

\begin{tabular}{|l|l|l|}
\hline \multicolumn{1}{|c|}{ Name } & \multicolumn{1}{|c|}{ Null } & \multicolumn{1}{c|}{ Type } \\
\hline Id_nilai & No & Int (11) \\
\hline Id_pegawai & Yes & Int (11) \\
\hline Id_Kriteria & Yes & Int (11) \\
\hline Nilai & Yes & Varchar (5) \\
\hline Id_user & Yes & Int (11) \\
\hline Periode & Yes & Int (8) \\
\hline
\end{tabular}

Tabel nilai digunakan untuk menyimpan hasil nilai yang berhubungan dengan penilaian kriteria masing-masing agen call center yang diberikan berdasarkan skala likert. Penulis menggunakan skala 1 sampai 4.
Tabel 7. Tabel Normalisasi

\begin{tabular}{|l|l|l|}
\hline \multicolumn{1}{|c|}{ Name } & \multicolumn{1}{c|}{ Null } & \multicolumn{1}{c|}{ Type } \\
\hline Id_normalisasi & No & Int (11) \\
\hline Id_pegawai & Yes & Int (11) \\
\hline Id_Kriteria & Yes & Int (11) \\
\hline Nilai_normalisasi & Yes & Varchar (5) \\
\hline
\end{tabular}

Tabel normalisasi digunakan untuk menormalisasikan setiap kriteria yang diberikan kepada agen call center agar tidak melebihi batas nilai normalisasi yaitu 1 atau kurang dari 1.

Tabel 8. Tabel Agen Call Center

\begin{tabular}{|l|l|l|}
\hline \multicolumn{1}{|c|}{ Name } & \multicolumn{1}{c|}{ Null } & \multicolumn{1}{c|}{ Type } \\
\hline Id_pegawai & No & Int (11) \\
\hline Nip & Yes & Varchar (15) \\
\hline Nama & Yes & Varchar (50) \\
\hline Jabatan & Yes & Varchar (40) \\
\hline Grade & Yes & Varchar (2) \\
\hline Cabang & Yes & Varchar (20) \\
\hline Tanggal_masuk & Yes & Varchar (15) \\
\hline
\end{tabular}

Tabel pegawai menyimpan informasi tentang data diri setiap agen call center yang bekerja dan dimonitoring secara langsung.

Tabel 9. Tabel Agen Periode

\begin{tabular}{|l|l|l|}
\hline \multicolumn{1}{|c|}{ Name } & \multicolumn{1}{|c|}{ Null } & \multicolumn{1}{c|}{ Type } \\
\hline No & No & Int (11) \\
\hline Periode & Yes & Varchar (100) \\
\hline Status & Yes & Int (11) \\
\hline
\end{tabular}

Tabel periode digunakan untuk meyimpan periode dan status dari kegiatan monitoring call center.

Tabel 10. Tabel Skala

\begin{tabular}{|l|l|l|}
\hline \multicolumn{1}{|c|}{ Name } & \multicolumn{1}{|c|}{ Null } & \multicolumn{1}{c|}{ Type } \\
\hline No & No & Int (11) \\
\hline Skala & Yes & Varchar (5) \\
\hline Percentage & Yes & Varchar (5) \\
\hline Inisial & Yes & Varchar (50) \\
\hline
\end{tabular}

Tabel skala untuk menyimpan skala yang digunakan dan persentase dari setiap per skala yang diberikan serta inisial setiap per skala.

\begin{tabular}{|l|l|l|}
\multicolumn{1}{|c|}{ Tabel 11. Tabel Skor Detail } \\
\begin{tabular}{|l|l|l|}
\hline \multicolumn{1}{|c|}{ Name } & \multicolumn{1}{c|}{ Type } \\
\hline Id_nilai & No & Int (11) \\
\hline Id-Pegawai & Yes & Int (11) \\
\hline Nama & Yes & Varchar (50) \\
\hline Id_kriteria & Yes & Int (11) \\
\hline Id-user & Yes & Int (11) \\
\hline Periode & Yes & Int (8) \\
\hline Skala & Yes & Varchar (5) \\
\hline Percentage & Yes & Varchar (5) \\
\hline Kriteria & Yes & Text \\
\hline Bobot & Yes & Varchar (5) \\
\hline Skor & Yes & double \\
\hline
\end{tabular}
\end{tabular}


Tabel skor detail digunakan untuk menyimpan informasi secara keseluruhan penilaian dari masing-masing setiap agen call center.

Tabel 12. Tabel Skor Summary

\begin{tabular}{|l|l|l|}
\hline \multicolumn{1}{|c|}{ Name } & \multicolumn{1}{|c|}{ Null } & \multicolumn{1}{c|}{ Iype } \\
\hline Id_pegawai & Yes & Varchar (50) \\
\hline Nama & Yes & Int (8) \\
\hline Periode & Yes & Double \\
\hline Skor tersebut digunakan untuk menyimpan dan \\
Tabel ter setiap \\
mengetahui siapa agen call center terbaik dari seriode. \\
penilaian yang diberikan per periode
\end{tabular}

Tabel 13. Tabel User

\begin{tabular}{|l|l|l|}
\hline \multicolumn{1}{|c|}{ Name } & \multicolumn{1}{|c|}{ Null } & \multicolumn{1}{c|}{ Type } \\
\hline Id_user & No & Int (11) \\
\hline Nama & Yes & Varchar (50) \\
\hline Jabatan & Yes & Varchar (100) \\
\hline Username & Yes & Varchar (30) \\
\hline Password & Yes & Varchar (100) \\
\hline
\end{tabular}

Tabel user digunakan untuk menyimpan informasi tentang user yang bertindak sebagai admin.

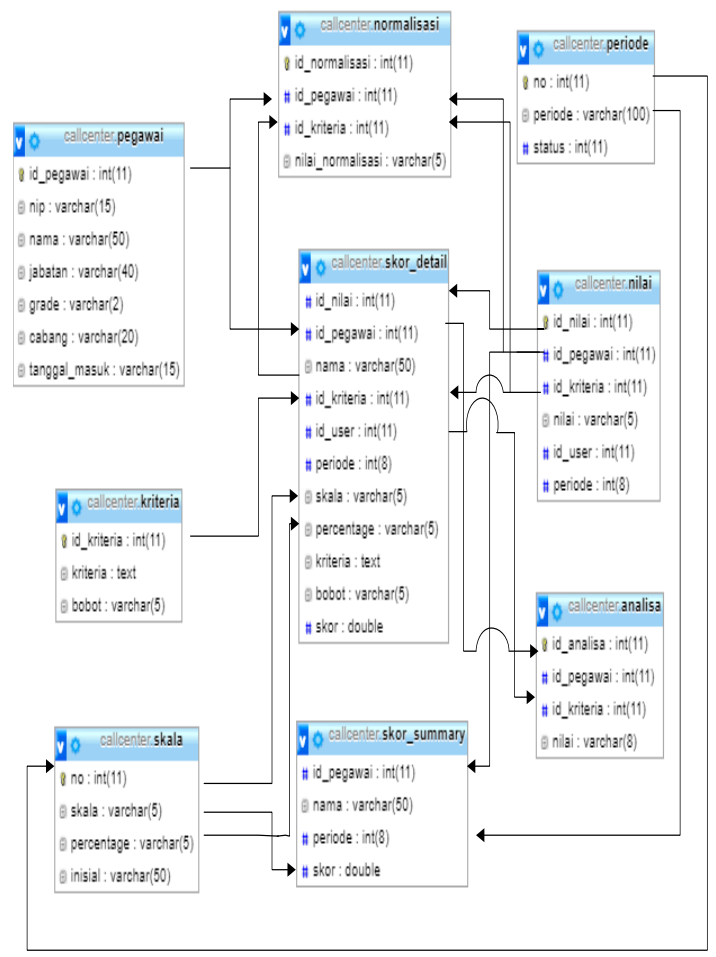

Gambar 3. Physical Model

\section{Rancangan Aplikasi Monitoring Call Center}

Setelah membuat perancangan sistem basis data ke dalam bentuk normalisasi dan dibuat menggunakan MySQL, maka berikut hasil perancangan aplikasi monitoring call center:

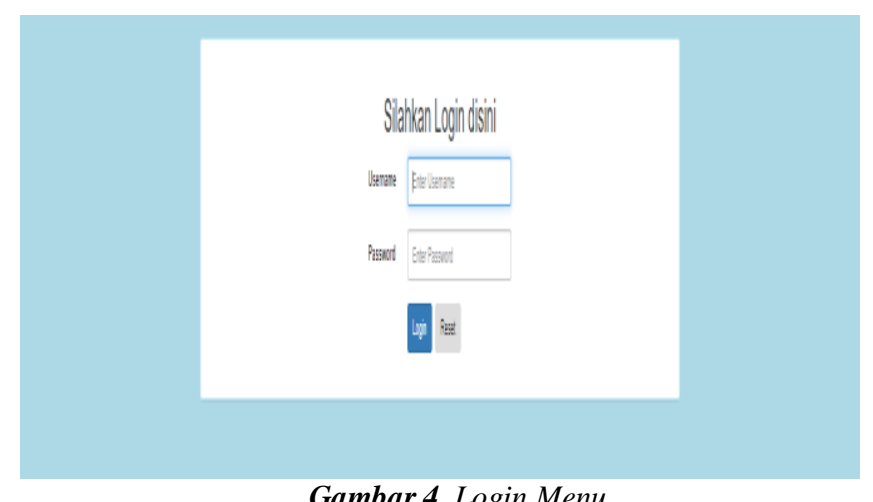

Gambar 4. Login Menu

Terlebih dahulu admin harus melakukan login berdasarkan username dan password yang sudah diregistrasi di database.

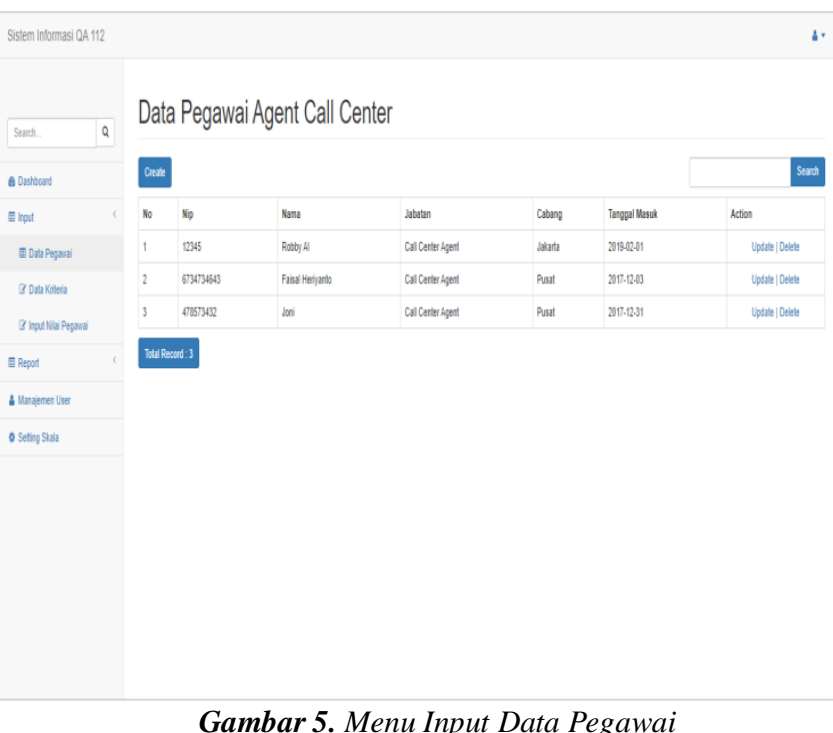

Dapat pada gambar 5 setelah admin login, admin menginput data pegawai yang bisa diupdate ataupun didelete.

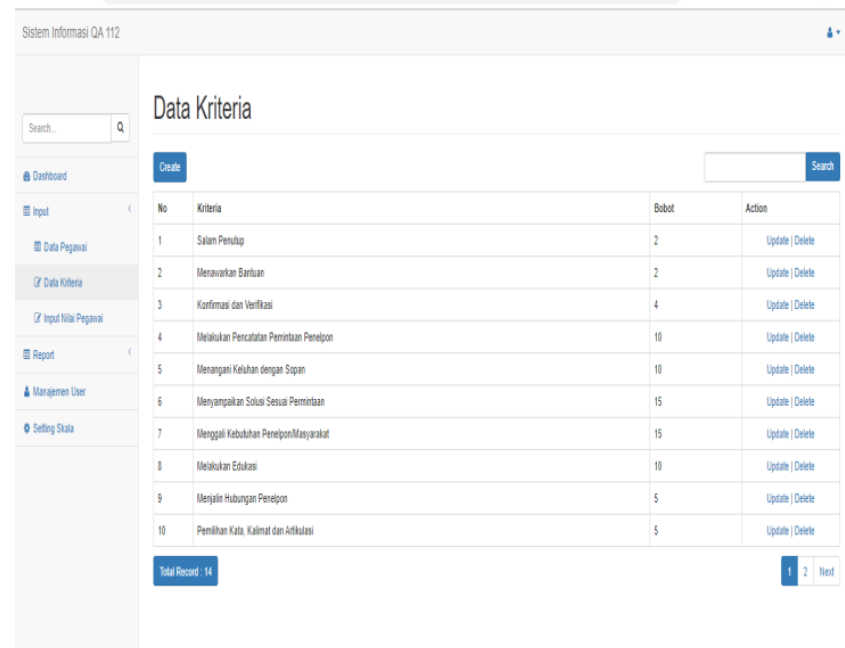

Gambar 6. Menu Input Data Kriteria 
Pada gambar 6, admin menginput data kriteria yang disesuaikan dengan data pegawai yang telah diinput. Data kriteria tersebut berjumlah 14 yang dimana setiap kriteria mempunyai masing-masing bobot (\%). Masing-masing pegawai dinilai berdasarkan pengamatan langsung oleh monitoring call center sehingga monitoring dapat berjalan dengan baik, diamati, dan dianalisa untuk mendukung keputusan terbaik apakah agen call center mempunyai kemampuan berdasarkan kriteria-kriteria tersebut.

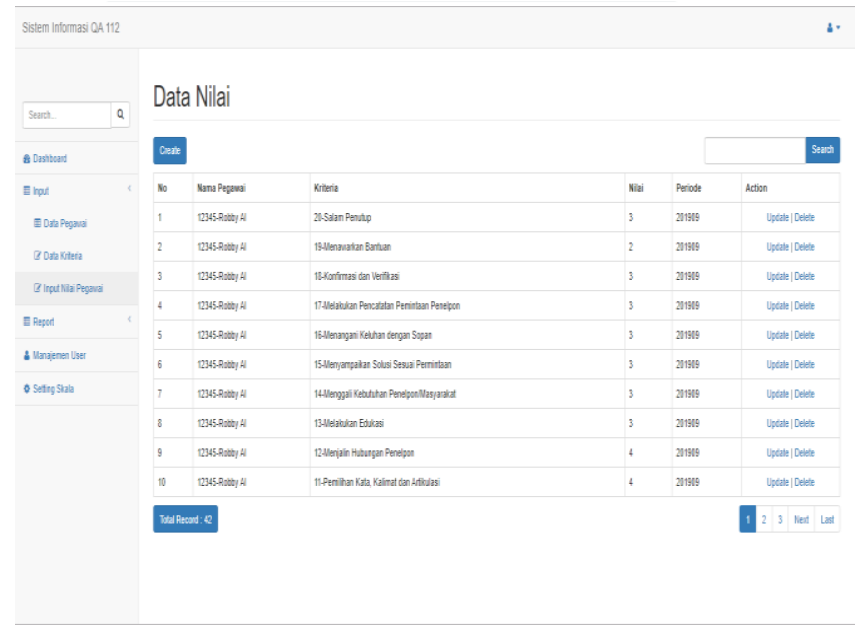

Gambar 7. Menu Input Data Nilai

Input data nilai pada gambar 7 berdasarkan score yang diberikan oleh monitoring. Setiap pegawai dinilai dengan tingkat keseriusan yang tinggi dimana tingkat score yang diberikan disesuaikan kembali dengan setiap bobot kriteria. Pada gambar 8 , setelah penginputan nilai pegawai, admin secara otomatis mendapatkan semua nilai setiap pegawai sehingga dapat terlihat keputusan pegawai mana yang mendapatkan score tertinggi berdasarkan pengamatan secara langsung sebagai report nilai setiap pegawai.

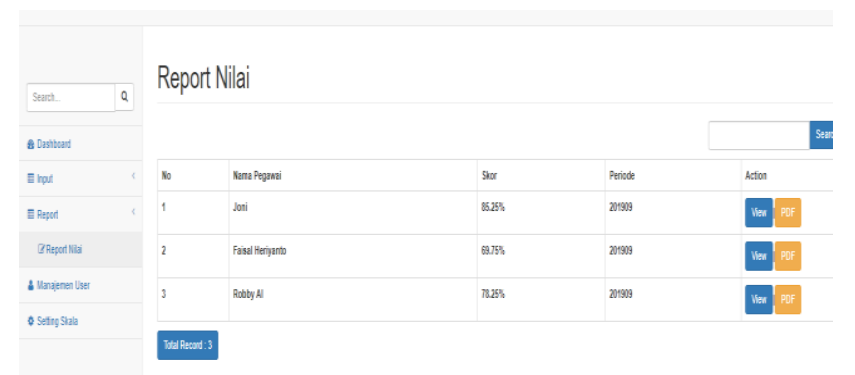

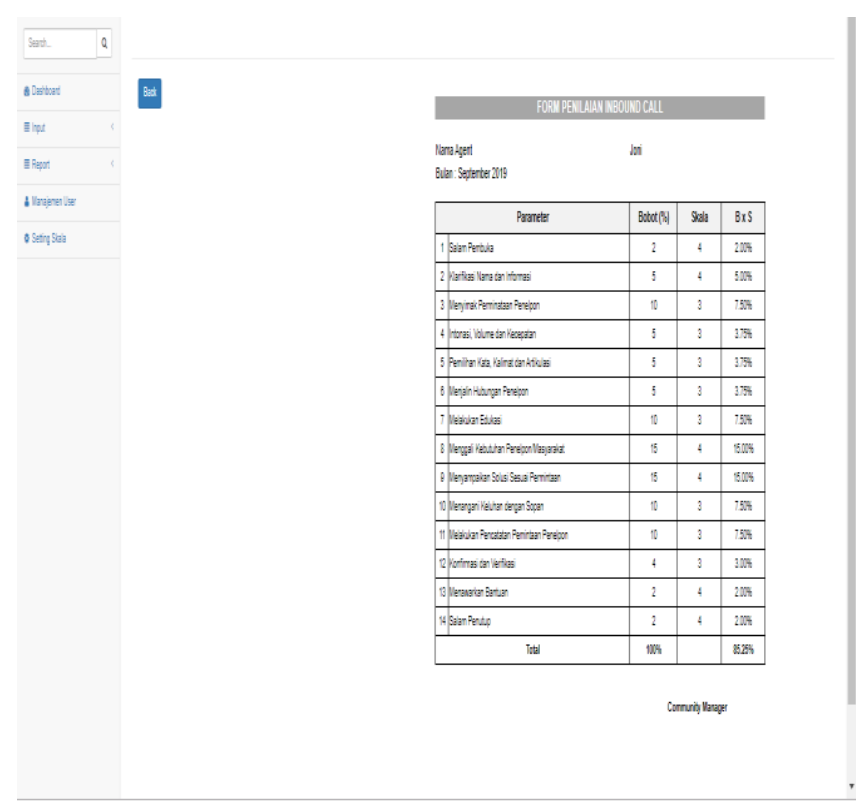

Gambar 9. Menu View Report Nilai

Pada gambar 9, report nilai masing-masing pegawai dapat dilihat secara langsung dan berbentuk pdf.

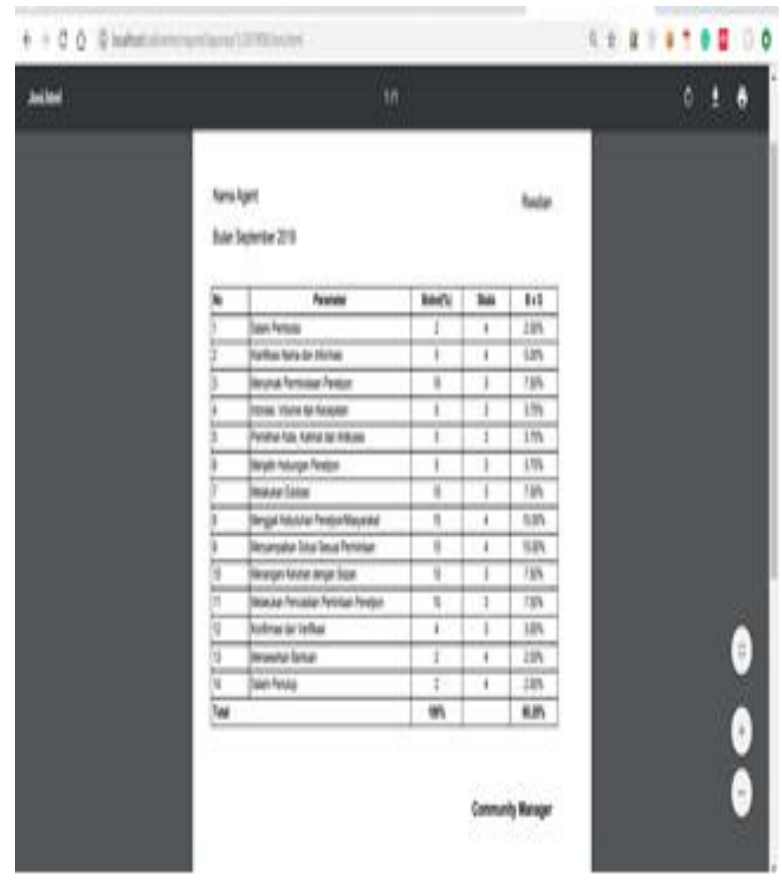

Gambar 10. Menu Report PDF.

Gambar 8. Menu Report Nilai 


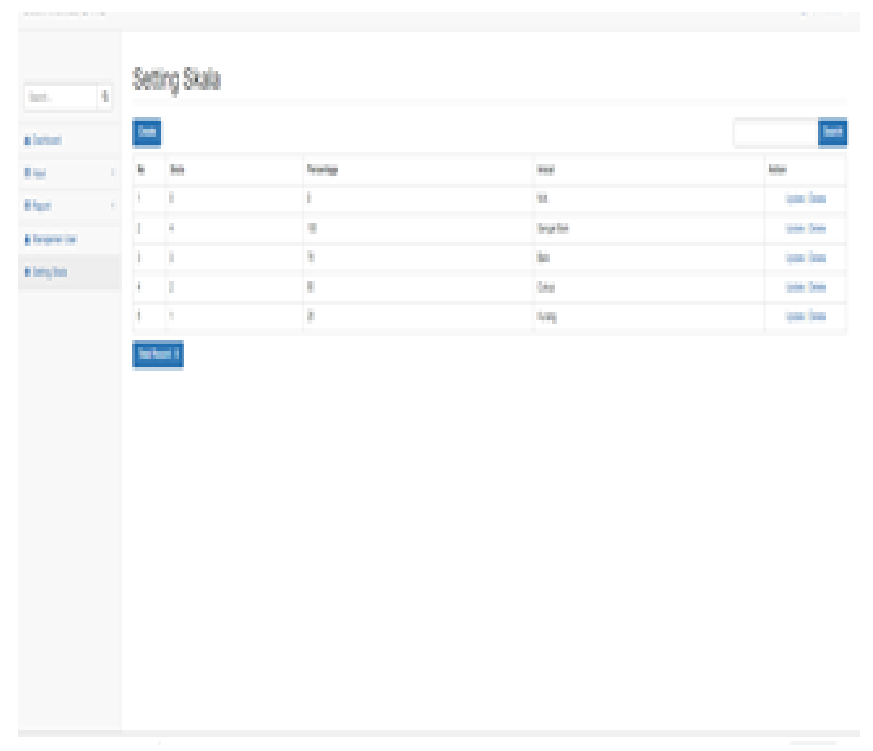

Gambar 11. Menu Setting Skala

Pada gambar 11, admin dapat setting skala dengan mengupdate nilai yang sudah ditetapkan.

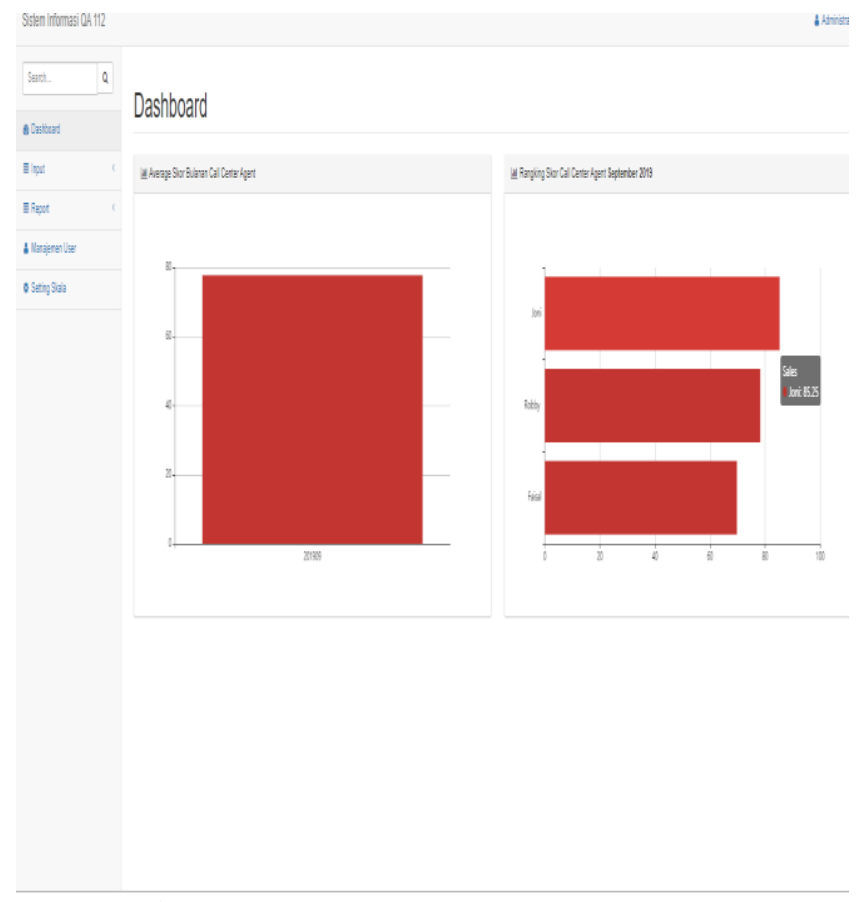

Gambar 12. Dashboard

Pada gambar tersebut dapat terlihat diagram yang secara otomatis didapat dari setiap penilaian agen call center sebagai ranking score setiap bulannya.

\section{SIMPULAN}

Berdasarkan pembahasan yang dilakukan oleh penulis, maka diambil beberapa kesimpulan sebagai berikut:

1. Aplikasi monitoring call center dapat mempermudah penilaian masing-masing pegawai atau agen call center berdasarkan pengamatan secara langsung yang dianalisa terlebih dahulu dan mendapatkan agen call center terbaik berdasarkan kriteria yang telah ada dan per periode.

2. Pengembangan sistem yang dibuat diharapkan sesuai dengan kebutuhan sistem maupun nanti diterapkan ke pihak BPBD DKI Jakarta.

3. Diharapkan sistem monitoring call center yang dikembangkan dalam sistem basis data untuk mengambil keputusan dapat membantu pihak terkait dalam menentukan agen call center terbaik sehingga dapat memicu agen lainnya agar bekerja lebih efektif dan efisien serta menumbuhkembangkan pelayanan terhadap masyarakat

\section{KEPUSTAKAAN}

[1] Mulyadi., Implementasi Sistem Basis Data untuk Mendukung Pengembangan Sistem Informasi Manajemen Sumber Daya Manusia (Studi Kasus : Stikom Dinamika Bangsa). Jurnal Ilmiah Media SISFO. Vol. 8 No. 2. P-ISSN 1978-8126, E-ISSN: $2527-$ 7340 (2014)

[2] Sudradjat, Adjat., Pengembangan Data Warehouse Call Center dengan Metodologi Kimball Nine-Step pada Bina Sarana Informatika. Jurnal Informatika Fakultas Teknologi Informasi Universitas Bina Sarana Informatika. Vol. 2, No. 2. P-ISSN: 23556579, E-ISSN: 2528-2247 (2015).

[3] Sucipto., Perancangan Active Database System pada Sistem Informasi Pelayanan Harga Pasar. Jurnal INTENSIF. Sistem Informasi Universitas Nusantara PGRI Kediri. Vol. 1, No. 1, ISSN: 2580-409X (Print), ISSN: 2549-6824 (Online). (2017).

[4] https://bpbd.jakarta.go.id/ diakses pada tanggal 25 Mei 2019

[5] https://id.wikipedia.org/wiki/Pusat_panggilan diakses tanggal 29 September 2019 